\title{
As possibilidades de análise dos fóruns de EaD sob a ótica das teorias discursivas e pós-modernas
}

\author{
Elizabeth Varges de Souza \\ PUC-Rio
}

\begin{abstract}
Resumo
A EaD vem gradativamente tornando-se uma opção de ensino-aprendizagem para um número crescente de pessoas, tenham elas como objetivo o aperfeiçoamento e a atualização profissional ou mesmo a formação acadêmica. Por este motivo, é essencial que nos proponhamos a investigar como as interações têm lugar nos fóruns de $\mathrm{EaD}$, cuja função primeira é a de simular o espaço de sala de aula, no qual alunos e tutores buscam coconstruir significados. Porém o fórum, assim como a sala de aula, é igualmente um espaço propenso a inúmeros conflitos, que precisam ser negociados no decorrer das interações. Partindo desta premissa, o presente trabalho se propõe a investigar algumas questões relativas à face e à polidez sob a ótica das teorias discursivas e pós-modernas, que são exemplificadas através da análise de parte de um fórum de educação a distância.
\end{abstract}

Palavras-chave: face, polidez, interação, fórum de EaD.

\begin{abstract}
Distance education has become a learning option for a growing number of people. No matter what the goals are - professional or academic, more and more people are looking for distance education courses. For this reason, it is essential that we investigate how the interaction between students and teachers occurs in the forums, since they are the classroom par excellence. Nevertheless, we need to bear in mind that, similarly to the classroom, the forum is a place of conflicts, which need to be negotiated discursively through interactions. Based on this assumption, this article aims to investigate some issues related to face and politeness from the viewpoint of discourse and post-modern theorists, as exemplified through the analysis of a distance education forum.
\end{abstract}

Keywords: face, politeness, interaction, forum

\section{INTRODUÇÃO}

A Internet vem constante e inexoravelmente rompendo qualquer tipo de barreira que porventura haja na comunicação entre os indivíduos, não somente no que diz respeito às formas de relacionamento, mas, principalmente, na maneira como as pessoas 
se relacionam. A possibilidade de o indivíduo participar das mais variadas redes sociais, e relacionar-se com outros cujos interesses são os mais diversos, possibilitou, como nunca antes visto na história da humanidade, que um sem número de pessoas pudessem se comunicar, não importando a hora ou o lugar do planeta em que se encontrassem. O mesmo ocorre com a escola, quando nos damos conta que, pouco a pouco, ela também vem se transmutando para a tela do computador, fazendo com que relacionamentos e interações característicos do espaço escolar cada vez mais tomem conta do ambiente online. Assim, o relacionamento entre alunos e entre alunos e mediadores passa a fazer parte do dia-a-dia de uma massa crescente de indivíduos, que veem na EaD uma oportunidade de aprimoramento e de crescimento profissional ao qual, de outra maneira, eles não teriam acesso.

É para este cenário tão característico deste início de século que voltamos nosso foco de pesquisa, no sentido de investigarmos como questões relativas à face e à polidez têm lugar nas interações que ocorrem em cursos a distância.

O caso específico deste estudo se refere a uma determinada situação de conflito entre mediadora e alunos em um fórum de EaD.

Assim, tendo constatado que o modelo proposto por Brown e Levinson não seria capaz de dar conta da complexidade da situação, voltamo-nos para modelos que pudessem nos fornecer uma análise o mais abrangente possível do que estava ocorrendo naquele momento e naquela circunstância tão particular.

\section{O MODELO DE BROWN E LEVINSON}

Em linhas gerais, o que especialmente caracteriza o modelo desenvolvido por Brown e Levinson (1987) é o fato destes assumirem que a comunicação entre falante e ouvinte não é passível de imperfeições e, consequentemente, de atos impolidos. Para eles, a pessoa é um modelo ideal que, através de um comportamento racional, tenderá sempre a assumir um comportamento cooperativo que levará à harmonia interacional e à ordem social, evitando assim confrontos e situações conflituosas. Baseando-se na teoria dos atos de fala, para Brown e Levinson (1987), a polidez é vista como um produto de estratégias racionais que tem por objetivo mitigar os atos de ameaça à face dos outros. Assim, eles vêem a face como a grande motivação para o comportamento polido, e mantém que esta consiste de dois aspectos que se relacionam: a face positiva e a face negativa, a primeira referindo-se ao desejo de aprovação da imagem própria por parte 
do indivíduo e a segunda ao desejo deste de não sofrer imposição, de não ter seu território invadido. Desta forma, segundo Terkourafi (2005), Brown e Levinson assumem uma hierarquia de cinco super-estratégias segundo o grau de risco de ameaça à face: direto sem ação reparadora, direto com ação reparadora (polidez positiva e polidez negativa), indireto e silêncio (ato de ameaça à face não realizado). Cientes também de que o fenômeno da polidez é igualmente extralingüístico, Brown e Levinson (1987) relacionam o uso da linguagem a variáveis sociais e afirmam então que, para decidir o tipo e grau de polidez que será utilizado, o falante deve levar em consideração a distância social que o separa do ouvinte, a relação de poder entre ambos e o grau de imposição daquele ato de fala em questão, o que deve ser considerado na interação.

Assim, ainda segundo Terkourafi (2005), os principais traços das teorias tradicionais são, primeiramente, seu foco Griceriano e, em segundo lugar, o foco nos atos de fala. No primeiro caso, ou seja, partindo do modelo proposto por Grice, a polidez é entendida como um afastamento maior ou menor do Princípio da Cooperação. Já na Teoria dos Atos de Fala há a preocupação em se analisar cada ato de fala, procurando, nas falas individuais de cada interagente, qual a estratégia de polidez utilizada.

Outro ponto bastante controverso e que tem sido continuamente criticado é a visão de que o modelo teórico da polidez é universal, sem levar em consideração a aplicabilidade de tal modelo nas diferentes culturas.

\section{PROBLEMATIZANDO OS MODELOS DE FACE E POLIDEZ DE BROWN E LEVINSON: AS TEORIAS DISCURSIVAS E PÓS-MODERNAS COMO BASE PARA AS ANÁLISES DE FÓRUNS DE EAD}

O modelo de polidez Brown e Levinson tem sido alvo de inúmeras críticas de autores pós-modernos, tais como Eelen (2001), Mills (2003) e Watts (2003), que entendem a polidez não mais como uma forma de cooperação para a preservação da face, mas como uma co-construção entre falantes e ouvintes, um produto da negociação com o outro. Porém, assim como Brown e Levinson, as teorias pós-modernas também dão mais ênfase à necessidade de face do ouvinte, contudo não mais apenas no sentido de falantes e ouvintes sustentarem a necessidade de face uns dos outros, mas sim de localizar a polidez nas avaliações dos ouvintes preferivelmente às intenções dos falantes. Tal fato, segundo Terkourafi (2005), leva as teorias pós-modernas a terem no 
gerenciamento do rapport, ou seja, no gerenciamento das relações, que inclui tanto as necessidades da face quanto os direitos de sociabilidade, um dos seus pontos mais relevantes. Assim, algumas dessas teorias rejeitam a teoria dos atos de fala e voltam seu foco para o discurso, passando a polidez a ser vista como um conceito dinâmico e situado, que está aberto a várias interpretações. Terkourafi (2005: 241) afirma que “a polidez não pode em princípio estar circunscrita a simples falas, mas é negociada em longos discursos, ou, como se pode complementar, ao longo de vários encontros.”1 Percebemos então que as normas desenvolvidas dentro de uma comunidade de prática é que são foco de atenção, e as não estratégias individuais.

Para Locher e Watts (2005: 10) a polidez passa a ser vista como uma das partes do trabalho relacional ${ }^{2}$, e "precisa ser vista em relação a outros tipos de significados interpessoais”. Esses autores fazem uma ligação entre o trabalho relacional e a noção de face de Goffman, na medida em que, para este último, a face não é parte inerente do indivíduo, mas sim construída discursivamente. Para Goffman, a face é atribuída socialmente a cada interação, o que implica que a um mesmo indivíduo possa ser atribuída um sem número de faces. Então, segundo Locher e Watts (2005), tal fato faz com que o termo "trabalho de face" possa ser estendido a todo relacionamento interpessoal, fato que o relaciona diretamente ao trabalho relacional, já que este abrange todo o comportamento verbal, seja ele polido ou impolido, o que acaba por englobar todas as formas de comportamento social. Ainda para estes autores, grande parte do trabalho relacional será de natureza não marcada; contudo, o comportamento marcado pode ser percebido de três formas: como negativo, que será considerado impolido, nãopolítico, inapropriado, ou como super-polido, não-político, inapropriado, e como positivo, que será percebido como polido, político e apropriado. Como estas categorias são negociadas no discurso, não há limites fixos entre elas. Assim, verifica-se que o trabalho relacional engloba uma noção bem mais abrangente de face do que aquela proposta por Brown e Levinson.

Tracy and Baratz (1994 apud Spencer-Oatey, 2009: 137) corroboram esta visão quando argumentam que "o objetivo da teoria de face deveria ser nos auxiliar a entender 'o que está acontecendo interacionalmente', e que, para que tal aconteça, precisamos [...] analisar o ato comunicativo como um todo, e não apenas os assuntos ligados à

\footnotetext{
${ }^{1}$ Politeness cannot in principle reside in single utterances, but it is negotiated in longer discourses, or, one might add, over several encounters.

${ }^{2} \mathrm{O}$ trabalho relacional consiste no trabalho investido pelo indivíduo na negociação dos relacionamentos com os outros.
} 
face.” Isto significa voltar o olhar para os objetivos interacionais de cada participante de modo mais abrangente, ou seja, analisar não apenas uma determinada atividade comunicativa, mas uma série de atividades.

Para Arundale (2006), a face emerge nos relacionamentos com outros atores sociais. Ele critica Goffman e, por conseguinte, Brown e Levinson, pelo fato de eles adotarem uma visão sócio-psicológica de face e terem seu foco em uma visão ocidentalizada de interagente. Arundale considera a face como um fenômeno emergente nos relacionamentos e, por este motivo, uma fenômeno relacional, o que significa também enquadrá-la como interacional. Assim “a face é uma interpretação que um participante faz quando se considera 'pessoas relacionando-se com outras pessoas'.” (Arundale, 2006: 202). A face então é um fenômeno diádico, e a pessoa um ser relacional, não individual. Arundale, baseando-se em Baxter e Montgomery (1996, apud Arundale, 2006), reconceitua o conceito de face negativa e face positiva de Brown e Levinson (1987), ou seja, relaciona a face positiva à idéia de conexão com o outro (connection face) e a face negativa à idéia de separação do outro (separation face), sendo que "conexão e separação serão expressas ou interpretadas diferentemente em tempos diferentes, em diferentes relacionamentos e em diferentes culturas.” (Arundale, 2006: 204).

Outro ponto que merece destaque é a mudança para um valor relacional tanto da face quanto do self social, o que implica que tanto o poder quanto a distância social são um fenômeno relacional, sendo ambos específicos, localizados e contextualmente gerados. A mudança para um modelo interacional implica que não existe elocução que seja inerentemente ameaçadora da face, e que tanto a ameaça quanto o apoio à face é uma avaliação dos participantes do que está ocorrendo em determinado momento na interação, e são conjuntamente co-construídas em um momento específico pelos interagentes.

O que podemos depreender das teorias discursivas pós-modernas é que, de uma forma ou de outra, todas procuram alternativas em relação ao modelo de Brown e Levinson. Alguns teóricos procuraram modificar a teoria destes autores incorporando elementos de outras tradições teóricas ao seu próprio modelo, outros, por o rejeitarem, tentaram desenvolver uma nova estrutura teórica. Há ainda aqueles que, segundo Mills (2009), tentaram ainda manter elementos do modelo proposto por Brown e Levinson, como Terkourafi (2005), por exemplo, que parte da teoria para analisar os dados e 
baseia-se em processos de implicatura. Contudo, seu olhar volta-se para o contexto, o que modifica significativamente a teoria de Brown e Levinson.

Assim, os teóricos que assumem uma abordagem predominantemente discursiva voltam seu foco de interesse para o contexto, e não mais para o uso de frases isoladas, o que tem implicações diretas no conceito de (im)polidez, já que estes autores não mais vêem sentido em associar-se as palavras em si à (im)polidez, pois nem a polidez nem a impolidez lhes são inerentes. Segundo Mills (2009: 5), “teóricos discursivos como Foucault $(1972 ; 1978)$ [...] têm demonstrado que os recursos disponíveis para os interagentes são moldados por forças sociais.” Tal como Goffman, muitos teóricos discursivos tendem a ver a questão da face como um processo dinâmico, negociado na interação, e não como algo estático, como preconizam Brown e Levinson. Voltando a Arundale (2009 apud Mills, 2009), este afirma que tanto a face quanto a polidez são negociados e alcançados na interação, não sendo apenas um grupo de normas partilhadas.

Outro ponto que merece destaque é o que diz respeito à impolidez. Em seu modelo teórico Brown e Levinson não contemplam exatamente a impolidez, e sim tendem a vê-la simplesmente como o oposto da polidez. Contudo, segundo Mills (2009), alguns teóricos como Locher (2004) e Bousfield (2007; 2008) defendem que a impolidez exerce uma função bem diferente da polidez, na medida em que, além da impolidez ser um ato verbal com a clara intenção de ameaçar à face, o uso da impolidez também parece estar relacionado à demonstração de poder sobre os interlocutores. Assim, é importante que examinemos o contexto em que o ato impolido tem lugar, já que este não surge do nada. Torna-se necessário então que o ato impolido seja examinado em seu contexto, considerando todas as variáveis, de forma a sabermos o que o provocou e quais seus efeitos sobre os interagentes. É importante ainda levar-se em consideração que muitos atos impolidos não têm exatamente a intenção de ofender, como colocam Locher e Watts (2005), mas de expressar raiva, aflição ou ainda reclamar de algo.

Assim, é bem pertinente a colocação de Pizzicone (2007 apud Mill, 2009: 13) quando esta afirma que "a língua não é uma realização intra-orgânica, mas interorgânica e, consequentemente, o resultado de validação mútua e de práticas sociais ... a língua não espelha, mas, ao invés disso, molda a realidade.” 


\section{OS FÓRUNS DE EAD - O PORQUÊ DO MODELO DE BROWN E LEVINSON NÃO SER SUFICIENTE PARA AS ANÁLISES}

Os fóruns de EaD são a sala de aula por excelência. Espaço de inúmeras vozes, são eles a principal ferramenta dos cursos a distância, pois são nos fóruns que alunos e professores/mediadores dão sentido ao que é aprendido, construindo, conjuntamente, aquilo que é partilhado e incrementado por todos, em um processo constante não apenas de interação, mas de colaboração. Assim, por ser este o espaço a ser utilizado como sala de aula, é que as relações, como em qualquer sala de aula presencial, vão aos poucos sendo construídas, e os alunos, com o apoio do mediador, vão formando uma comunidade de prática, assim como descrita por Wenger (1998):

Grupos que partilham de objetivos e interesses parecidos e que, devido a isso, empregam práticas comuns, trabalham com as mesmas ferramentas e se expressam através de uma linguagem comum. Através destas atividades comuns, estes acabam por partilhar crenças e sistemas de valores semelhantes. (Collaborative Visualization Project, 2000; Wenger, 1998; apud Tu \& Corry, 2002: 7)

Entretanto, não podemos ignorar que, como em qualquer ambiente de ensinoaprendizagem presencial, a sala de aula virtual também é um espaço de conflitos, onde há relações de poder que podem estar explícitas ou não, assim como expectativas em relação à atuação do mediador que, naquele espaço, traz em si a figura do professor, com todas as implicações que isto possa trazer.

O fórum para o qual volto minha atenção, e que já foi objeto de minha investigação anterior, é intitulado Desabafo. Analisei este fórum em minha dissertação de Mestrado $^{3}$ baseando-me na teoria da polidez e na noção de face propostas por Brown e Levinson, e volto agora a este mesmo fórum, porém com um outro olhar - aquele das teorias discursivas e pós-modernas que, acredito, proporcionarão um entendimento mais abrangente e acurado do que ocorreu naquele momento, naquela interação específica.

Em linhas gerais, o fórum em questão trata do descontentamento de um grupo de alunos em relação ao trabalho da professora/mediadora. Tal sentimento é expresso na mensagem de abertura do fórum, fato que desencadeia toda uma série de reclamações e críticas culminando com o desentendimento entre os próprios alunos. É pertinente ressaltar o contexto no qual este fórum se insere, pois, antes deste ser aberto, já havia

\footnotetext{
${ }^{3}$ Souza, E.V. “Desabafo”: Análise da interação em fóruns de EaD. Rio de Janeiro, 2008. 190 p. Dissertação de Mestrado - Faculdade de Letras, PUC-Rio.
} 
certa insatisfação dos alunos em relação à atuação da tutora, que não mantinha uma constância aceitável nos fóruns, o que foi comprovado em meu trabalho anterior.

Assim, neste fórum específico, gostaria de abordar a questão da face como fenômeno relacional (negociação de relacionamentos) e interacional, e da polidez como um trabalho de face, que passa as ser vista não somente como forma de minimizar os atos de ameaça à face, como em Brown e Levinson, mas como conceito dinâmico, situado e aberto a interpretações, passando esta então a ser considerada um conceito discursivo. O motivo para esta escolha recai no fato de que o que acontece nesta interação não é simplesmente uma questão de desejo individual, ou da simples codificação e decodificação de significados, mas sim de pessoas que se posicionam e se comunicam continuamente dentro e a partir de relacionamentos específicos. Desta forma, tomando como ponto de partida a natureza dialógica dos relacionamentos humanos, chega-se à noção de face como "propriedade emergente dos relacionamentos, e, consequentemente, um fenômeno relacional.” (Arundale, 2006: 201). Aliado a este fato, enquadrar a face como relacional significa enquadrá-la igualmente como interacional, pois ela é uma "interpretação que um participante forma levando em consideração ‘pessoas-se-relacionando-com-outras-pessoas'”, ou, mais precisamente, “a interpretação de um participante de pessoas conectadas e separadas de outras pessoas.” (Arundale, 2006: 202, 204). Outro ponto relevante a se levar em conta na análise do fórum é quanto à questão de poder e distância social que, em uma sala de aula tradicional, se traduz na relação professor-aluno. Porém, na mudança para um modelo relacional do self social e da face, temos que tanto o poder quanto a distância social são fatores localizados no contexto, gerados no contexto e que se tornam relevantes para aqueles atores envolvidos naquela interação específica.

A mudança para o modelo interacional implica também que nenhuma elocução é inerentemente ameaçadora da face ou codificadora de qualquer significado ou ação relacionados à face. Assim, tanto a ameaça quanto o apoio à face são apreciações dos participantes, e não se resumem à implicaturas conversacionais acionadas simplesmente por estratégias verbais.

Assim, percebemos que há questões ligadas à tradição de pesquisa que o modelo de Brown e Levinson não abarca. Em relação à polidez, Locher e Watts (2005) afirmam que estes autores não lidam exatamente com questões de polidez, mas sim com mitigação de atos de ameaça à face, além do fato da impolidez ser considerada somente como o oposto da polidez e, talvez por este mesmo motivo, não ter sido foco de atenção. 
Contudo, segundo Locher e Watts (2005), o trabalho relacional inclui tanto a polidez quanto a impolidez, assim como também o comportamento apropriado. É importante ainda levar-se em consideração que muitos atos impolidos não têm exatamente a intenção de ofender, como colocam Locher e Watts (2005), podem ser a expressão de raiva, aflição ou de uma reclamação, como mencionado anteriormente.

Voltando então ao fórum, percebemos que o propósito da interação como um todo é o de reclamar da falta de participação do grupo nos fóruns e do sumiço da tutora.

Analisarei algumas das mensagens postadas com o intuito de exemplificar o que foi colocado até este momento, no sentido de entender "o que os interagentes demonstram em sua fala para os outros, e o que isto pode dizer aos outros interagentes sobre onde eles se vêem no grupo, como eles vêem o grupo e que valores eles assumem são mantidos pelos membros do grupo.” (Mills, 2009: 9)

O aluno Cristiano, em sua mensagem inicial, relata os problemas que ele acredita ser de todos, ou ao menos de grande parte do grupo. O relato, ao qual ele denomina Desabafo, é uma construção de face. Ele se coloca como aquele que tem a coragem de tomar a iniciativa de reclamar de uma situação aparentemente insatisfatória. Além disso, ele toma para si o direito à reclamação por se colocar como o aluno que está sempre presente, que participa de todas as atividades, e que, exatamente por este motivo, pode fazer reivindicações sem ter sua face ameaçada. Há também o fato que, por ser esta uma comunidade de prática, já há algum tempo trabalhando em conjunto, haver a expectativa, ou a quase certeza, de que as reivindicações e reclamações serão apoiadas pelo grupo. Percebemos também em seu discurso um grande número de clichês, como uma lição que foi decorada, e mesmo certo exagero de retórica, quando ele fala em “Construir uma nova história...”. A sua indiretividade também incita o conflito, pois o que é dito nas entrelinhas pode ser interpretado de diferentes formas por diferentes pessoas. Não é apenas uma questão da utilização de uma estratégia (no caso, de indiretividade), mas de todo um trabalho relacional que vai sendo feito com o objetivo fim de fazer com que os outros cursistas o apóiem na reclamação. De fato, pelas respostas dos outros participantes, percebemos que os alunos seguem o mesmo enquadre e se alinham com Cristiano.

O trabalho relacional que se delineia neste início do fórum é delicado, pois pelas respostas dos outros alunos à reivindicação de Cristiano, percebemos haver uma orientação para um conflito que, aos poucos, vai se delineando, como podemos verificar nas mensagens a seguir. 
Desabafo

por CRISTIANO - quinta, 1 fevereiro, 09:15

Será que estou errado? Cego, talvez?

Onde estão os todos aqueles posicionamentos críticos e inflamados desta turma? Onde estão todos? Onde está a Tutora que pouco aparece?

Todos vocês são partes muito importantes p'ra mim. Só através de nossa interação é que estou conseguindo apreender tantos e tantos conhecimentos. Só assim estou conseguindo aprender a aprender... Construir uma nova história...

Será que estou "viajando" ou realmente existe certo desânimo no ar? Estamos rumo à reta final... E aí?

E somente pelos debates acalorados que me incentivaram durante todo o tempo é que estou aqui. Como diria aquele "Menino": "Você é responsável pela alma que cativa”... E a turma me cativou...

O que vocês dizem? Ou será que...

Abraços a todos!

Cristiano

Re: Desabafo

por ALEX - quinta, 1 fevereiro, 09:25

Você está certo, Cristiano. Creio que está ocorrendo um certo desânimo mesmo.

Re: Desabafo

por LUCINDA - quinta, 1 fevereiro, 09:59

Oi Cristiano!

Você está certíssimo!

Pelo menos da minha parte há um desânimo muito grande. E isso já vem acontecendo há tempos, desde quando fazia parte da outra turma.

Já me coloquei algumas vezes, questionei a presença das tutoras, que a meu ver não está satisfatória, a demora em obter as respostas, que na maioria das vezes não esclarecem absolutamente nada, pelo contrário, só confundem mais.

Percebo que nada mudou, continuamos no mesmo barco, cheios de dúvidas e sem perspectivas de respostas objetivas e esclarecedoras.

Não há motivação que resista, você há de concordar comigo, não é?

Um abraço,

Lucinda

Re: Desabafo

por OTÁVIO - quinta, 1 fevereiro, 10:17

Grande Cristiano!

Como você, tenho observado certo desânimo neste último módulo; eu mesmo tenho participado pouco nos debates. Atividades pouco desafiadoras, enunciados confusos, objetivos sem clareza, prazos indefinidos, tutora ausente, a demora em obter respostas e, claro, rumo à reta final do curso.

Vamos tentar reverter este quadro?! 
Abs.

Otávio

Contudo, um fato que não deve ser perdido de vista é o de que, como já mencionado anteriormente, os fóruns de EaD são a sala de aula por excelência e, como tal, englobam determinados atores - alunos e professores, com determinados papéis sociais a ser desempenhados. Assim, o enquadre de sala de aula vem acompanhado de estruturas de expectativa passadas (Tannen, 1993 apud Locher e Watts, 2005) que nos predispõe a agir de determinada maneira nesta situação específica, o que significa que tendemos a trazer para a sala de aula on-line as mesmas normas sociais existentes na sala de aula presencial. Tendo isto em mente voltemos aos fóruns. Tal qual em uma situação presencial, a relação professor-aluno envolve poder, distância social e grau de imposição. Porém, verificamos que, na sala de aula on-line, pelas próprias características do ambiente, estruturas de expectativa passadas podem levar a conflitos e desentendimentos que não necessariamente ocorreriam em uma situação presencial. Iniciando pelo fato de o professor, presencialmente, não “desaparecer” da sala de aula por semanas, algo como se os alunos comparecessem, mas nunca houvesse ninguém lá, além deles mesmos. Neste caso, tal fato certamente levaria à mudanças nas regras sociais, pois este ambiente ficaria descaracterizado, não mais sendo reconhecido como uma “aula-de-aula-professor-alunos”. Descaracterizado o ambiente, a questão do poder e da distância social entre alunos e professores ficaria comprometida. E é justamente neste cenário que os alunos do fórum em questão se encontram. Não há mais o reconhecimento daquele ambiente como sendo o de uma sala de aula e, por este motivo, as regras sociais não são mais, necessariamente, as mesmas.

Tal fato nos leva à constatação de que tanto o poder quanto a distância social são fenômenos relacionais, gerados localmente em determinado contexto e relevantes para aquela interação específica. Quando os alunos corroboram as reclamações feitas, orientando-se para uma relação conflituosa, eles passam a não mais reconhecer haver uma relação de poder entre professor e alunos ou as regras sociais inerentes a esta relação, sendo que tal situação cada vez mais frequentemente vem ocorrendo em ambientes pedagógicos, sejam eles presenciais ou a distância.

Como afirma Spencer-Oatey (2009), o objetivo da teoria de face deveria ser nos auxiliar no entendimento do que está acontecendo na interação, sendo para isso 
necessário que nos orientemos para a ação e que vejamos o ato comunicativo como um todo, e não somente os assuntos ligados à face.

Cabe-nos então fazer uma última análise de uma postagem colocada pela aluna Carla.

Re: Desabafo

por CARLA - quinta, 1 fevereiro, 11:07

Estimado colega Cristiano,

Sei como se sente.

No curso EAD, nossa presença física é substituída pela palavra escrita, e se não a usamos é como se tivéssemos desaparecido, evaporado, ficado só.

No curso presencial, m esmo que nossos pensamentos estejam longe da sala de aula, nosso corpo está presente, dizendo estou aqui.

Já no curso a distância, onde não podemos exprimir nossos pensamentos através de um abraço, um sorriso, um olhar, tem um único recurso, exprimir nossos pensamentos através da PALAVRA escrita. Essa é uma importante ferramenta, temos que aproveitala ao máximo, pois podemos tudo com ela.

Essa é minha primeira experiência num curso a distância. Fiquei surpresa em observar a sutil criação de laços de carinho, amizade, ajuda, companheirismo entre os componentes do grupo, isso tudo foi fruto dos laços criados através da interação, portando se deixarmos de interagir, essa chama se apaga.

Portanto Cristiano e queridos colegas podem contar comigo para manter acesa essa chama de amizade e companheirismo criada por nós, neste curso. Lembrando que, nosso objetivo principal é aprimorar nossos conhecimentos nos tornando pessoas mais capacitadas, portanto melhores.

Sintam-se abraçados,

Carla

Nesta mensagem podemos perceber a preocupação da aluna em tanto dar apoio à necessidade de face de Cristiano, o que ela deixa claro logo no início da mensagem ao dizer "Estimado ... sei como se sente" quanto de assumir uma posição mais conciliadora, e por esta razão, menos comprometedora. A sua oferta não é a de se juntar ao grupo na reclamação. O que ela oferece é amizade e companheirismo, sutilmente lembrando a todos o que ela acredita ser o objetivo principal de estarem ali. Carla não faz uso de estratégias (grifo meu) de polidez, mas seu discurso é indiscutivelmente uma construção de face, na qual ela clama para si determinados atributos, como a de conciliadora, empática e amiga. Não diria que seu comportamento foi exatamente polido, mas sim político. Como diz Bourdieu (1990 apud Locher e Watts, 2005: 16), “it's her feel for the game", ou o que ela considera ser um comportamento socialmente apropriado. 
A mensagem da tutora, inserida abaixo, evidencia como ela faz o gerenciamento do rapport, ou seja, como ela gerencia seu relacionamento com os alunos.

\section{Re: Desabafo/resposta TT}

por LUCIANA - quinta, 1 fevereiro, 12:20

\section{Então Cristiano}

Algumas questões devem ser colocadas. Conversei com a Vilma sobre estas insatisfações assumindo minhas falhas:

1) Não fomentei este fórum na medida da necessidade de vocês;

2) Voltei-me para os problemas grupais, (como por exemplo dúvidas indicadas por email) e leituras dos trabalhos;

Diante destas demandas apresentadas neste debate repleto de insatisfações acho que poderíamos recolacar nossa posição. Vamos tentar animar e avançar no trabalho coletivo bem como no trabalho individual, Cristiano.

Não é a promeira vez que erramos.

Acho que vocês passarão por isso ou já passaram. Essa experiência não é a primeira, mas é como se iniciássemos algo novo em cada projeto no qual estamos inseridos.

Por favor, não deixe que este "desabafo" contamine nossas práticas futuras.

Gostaria de dizer, outra vez que não sou "adrenalina pura". Coisas que os alunos em

EAD não podem dar conta pela ausência de contato. Gostaria também que esses pontos

fossem melhor observados via e mail (as insatisfações) sobretudo as suas que

apareceram com maior força. Você cumpre um papel fundamental neste momento.

Aguardo suas ressalvas via e mail, Cristiano

Obrigada

Luciana

Como coloca Spencer-Oatey (2000), dois componentes estão aqui envolvidos, e podemos percebê-los claramente: o gerenciamento da face e o gerenciamento dos direitos de sociabilidade. O primeiro aparece quando ela assume suas falhas. Ao tomar tal atitude a tutora estaria atenuando problemas relacionados à sua reputação e competência, colocando-se como uma profissional que admite seus erros e se propõe a repará-los. Porém há um problema de incoerência em seu discurso, pois o que ela coloca como problemas grupais, são, na verdade, problemas individuais, o que faz com que sua competência continue a ser questionada. Ainda segundo Spencer-Oatey, a face qualitativa (quality face) da tutora foi ameaçada, como mencionado anteriormente. Contudo, além disso, sua face identitária (identity face) foi igualmente ameaçada, pois o aluno Cristiano, e posteriormente, outros do grupo, o fizeram em público, ou seja, sua posição de membro mais experiente do grupo, aquela que, em princípio, os deveria orientar, foi abertamente questionada. Uma forma de ter este problema solucionado, ou ao menos minimizado, é o de direcionar as reclamações para o e-mail, ou seja, fazer com que elas se tornem privadas, o que ela sugere aos alunos de forma a evitar uma 
exposição maior perante a turma. A tutora tenta gerenciar seus direitos de sociabilidade quando pede (Gostaria também que esses pontos fossem melhor observados via e mail (as insatisfações) sobretudo as suas que apareceram com maior força. - grifo meu) que as reclamações mais contundentes sejam enviadas por e-mail, esperando maior consideração por parte dos alunos, o que ela imagina ser o tratamento mais justo, até por não considerar-se adrenalina pura. É desta forma que a tutora tenta equilibrar as tensões que surgem. Percebemos também que ela demonstra preocupação com o futuro de seu curso (Por favor, não deixe que este "desabafo" contamine nossas práticas futuras.) o que certamente orienta tanto seu trabalho relacional quanto seus objetivos interacionais.

\section{CONCLUSÃO}

O que procurei demonstrar com este trabalho foi como as teorias discursivas e pós-modernas podem ampliar nossa compreensão do que acontece nas interações, tornando claro, através da análise de algumas mensagens contidas num fórum de $\mathrm{EaD}$, que o modelo proposto por Brown e Levinson, baseado em atos de fala, implicaturas e estratégias de polidez, não consegue dar conta do que ocorre discursivamente nas interações. De forma geral, o que se percebe é que os estudiosos e teóricos pósmodernos têm visões semelhantes, diferindo basicamente no foco de seus estudos. Há uma linha que perpassa todas essas teorias e, mantidas as diferenças e singularidades de cada uma delas, percebemos haver vários pontos de contato que, de certa forma, as une. Exatamente por este motivo procurei traçar um panorama de tais teorias a fim de que, a partir delas, pudéssemos compreender melhor como, através do trabalho relacional, os seres humanos se comunicam, cooperativamente ou não. Como afirmam Locher e Watts (2005: 29), “dependendo do tipo do comportamento social verbal no qual os indivíduos se empenham, eles adaptarão seu trabalho relacional para o que eles consideram apropriado.”

Este trabalho não tem a intenção de fazer uma análise ampla do fórum em questão, mas de demonstrar como, especialmente em ambientes de educação a distância sem momentos presenciais, tais análises podem ser utilizadas como subsídio para que possamos compreender a forma como alunos, professores e os demais envolvidos neste tipo de ensino-aprendizagem interagem, se comunicam e constroem significados. 


\section{REFERÊNCIAS}

Arundale, R. (2006). Face as relational and interactional: a communication framework for research on face, facework and politeness. Journal of Politeness Research, 2, 193217.

Bargiella, F. (2003). Face and politeness: new (insights) for old (concepts). Journal of Pragmatics, 35, 1453-1469.

Brown, P., Levinson, S. (1987). Politeness: some universal in language usage. Cambridge: Cambridge University.

Eelen, G. (2001). Critique of politeness theories. Manchester: St. Jeromes Press.

Goffman, E. (1955). On face work: an analysis of ritual elements in social interaction. Psychiatry 18 (3): 213-231

Locker, M. A., Watts, R. J. (2005). Politeness theory and relational work. Journal of Politeness Research, 1, 09-33.

Mills, S. (in prep.). Discursive approaches to politeness. Chapter 1: Discursive approaches to politeness and impoliteness.

Souza, E.V. (2008). "Desabafo": Análise da interação em fóruns de EaD. Tese de Mestrado inédita, PUC-Rio.

Spencer-Oatey, H. (2000). Culturally Speaking: Managing Rapport through talk across cultures. London: Continuum.

. (2009). Face, identity and interactional goals. In: Bargiela-Chiappini, F.; Haugh, M. Face, communication and social interaction. London: Equinox.

Terkourafi, M. (2005). Beyond the micro-level in politeness research. Journal of Politeness Research, 1, 237-262.

Tu, C.H. and Corry, M. Research in Online Learning Community. Disponível em: $<$ http://www.usq.edu.au/electpub/e-jist/docs/html2002/pdf/chtu.pdf $>\quad$ Acesso em $11 / 2007$.

Watts, R. (2003). Politeness. Cambridge: Cambridge University Press.

\section{A AUTORA}

Elizabeth Varges de Souza possui graduação em Letras (Português-Inglês) pela Universidade do Estado do Rio de Janeiro, especialização em Língua Inglesa pela mesma Universidade e especialização em EaD pelo Senac-Rio. Concluiu o Mestrado na PUC-Rio em 2009, tendo especial interesse nas áreas de Linguística Aplicada, Análise 
do Discurso e Educação a Distância. Atualmente cursa o Doutorado também na PUCRio, e tem dado sequência aos estudos iniciados no Mestrado.

e-mail: evarges@uninet.com.br 